\title{
Anti-aging effects of black raspberry extract on cataract, alopecia, skin whitening, and weight loss
}

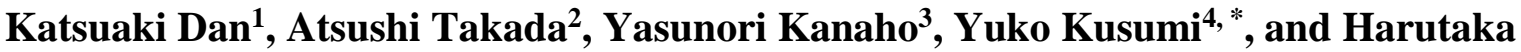 \\ Banno $^{4, *}$
}

${ }^{1}$ Division of Research and Development, Research Organization of Biological Activity, 18 Shinanomachi, shinjyuku-ku, Tokyo 160-0016, Japan; ${ }^{2}$ NPO for natural \& healthy skins in environment, 2-23-4 Nakazato, kita-ku, Tokyo 114-0015, Japan; ${ }^{3}$ Department of Physiological Chemistry, Faculty of Medicine and Graduate School of Comprehensive Human Sciences, University of Tsukuba, 1-1-1 Tennodai, Tsukuba 305-8575, Japan; ${ }^{4}$ INNATUS Co. Ltd., 2-1-14 Higashi-tabata, kita-ku, Tokyo 114-0013, Japan

Corresponding authors: Harutaka Banno and Yuko Kusumi, INNATUS Co. Ltd., 2-1-14 Higashi-tabata, kita-ku, Tokyo 114-0013, Japan

Submission Date: September $3^{\text {rd }}$, 2017, Acceptance Date: December $27^{\text {th }}$, 2017, Publication Date: January 31st, 2018

Citation: Dan K, Takada A, Kanaho Y, Kusumi Y, Banno H: Anti-aging effects of black raspberry extract on cataract, alopecia, skin whitening, and weight loss. Functional Foods in Health and Disease 2018, 8(1):17-34. DOI: https://doi.org/10.31989/ffhd.v8i1.389

\begin{abstract}
Background: To maintain good health, it is important to eliminate extra reactive oxygen generated in the body. Furthermore, ingesting foods containing antioxidants is beneficial. The oxygen radical absorbance capacity (ORAC) values for black raspberry extract (BRE), blueberry extract (BBE), and raspberry extract (RBE) are 62, 66, and $49 \mu \mathrm{M}$ Trolox equivalents (TE)/g respectively. These values are higher than those for typical antioxidant foods that have been discovered so far (3-30 $\mu \mathrm{M} \mathrm{TE} / \mathrm{g})$. Our aim was to find new functionality from the food with the high ORAC value. Therefore, we have prepared these four berry extracts and examined whether they have anti-aging effects and if those effects correlate with their antioxidant activities.
\end{abstract}


Methods: We studied the following effects of 4 berry extracts: 1) lens cell protective effects; 2) effects against alopecia; 3) induction of uncoupling protein-1 (UCP1), a regulator of fat and energy consumption in adipocytes, and stimulation of irisin secretion from skeletal muscle cells; and 4) inhibitory effects on melanocyte tyrosinase activity. The evaluation method was based on below; 1) a-crystallin, type 17 collagen, heat shock protein 47 (HSP47), UCP1 and Irisin mRNA by qRT-PCR, 2) the amount of the UCP1 and Irisin protein by ELISA. 3) Inhibition of tyrosinase activity was measured by dopachrome production using L-tyrosine.

Results: In lens cells, $\alpha$-crystallin mRNA expression was induced 1 hour after treatment of the cell with Blabina (a powdered formulation containing BRE) and BRE. The extracts of all four berry species promoted the growth of follicle dermal papilla cells by $3-20 \%$ in a concentration-dependent manner. These berry extracts were also discovered to markedly induce the expression of mRNAs of type 17 collagen and HSP47 in the hair follicle stem cell and elevate the expression levels of UCPI mRNA and its protein in adipocytes in a concentration-dependent manner. BRE and Blabina inhibited 5 $\alpha$-reductase in follicle dermal papilla cells and tyrosinase activity in melanocytes at the concentrations which inhibited dopachrome production by at least $50 \%$. Finally, Blabina was discovered to stimulate the irisin secretion from skeletal muscles.

Conclusion: These results suggest that berry extracts, particularly BRE, have anti-aging effects through their higher antioxidant activities.

Keywords: Anti-aging, antioxidant, alopecia, black raspberry, weight loss, oxygen radical, absorbance capacity, skin whitening

\section{INTRODUCTION}

Oxygen is essential for most organisms within human beings. A proportion of oxygen inhaled is converted into reactive oxygen species (ROS), which are utilized for protection against invaded bacteria. Additionally, excessive amounts of ROS can be generated by ultraviolet light, smoking, exhaust gas, air pollution and stress, and causes oxidative damages to body tissues [1]. As a result, wide variety of diseases such as lifestyle-related diseases, cancer, and dementia occur. It is estimated that more than $90 \%$ of all diseases have a causal relationship with excess ROS production [2]. Therefore, excessive amounts of ROS must be eliminated from the human body 
by antioxidant enzymes and exogenous substances to maintain homeostasis and prevent these diseases. Recently, antioxidant substances existing in foods are attracting attention for the potential treatment and prevention of disease and methods to evaluate antioxidant capacity and the oxygen radical absorbance capacity (ORAC) of foods have been established and are widely used [3]. The ORAC is a measurement system developed by the United States Department of Agriculture to evaluate the antioxidant capacity of foods and supplements, and a list of the top 100 of antioxidant foods with high ORAC values including 12 food items containing berries [4]. The relation with ORAC has been considered with Fucoidan, grape wine, apple cider vinegar, Faba bean flour, and more [5-8].

In addition to lifestyle-related diseases, aging-associated events such as the cataract, alopecia, obesity, and skin pigmentation are serious issues for older humans. The cataract results from aging-associated development of opacity of the eye lenses, and occurs in virtually everyone over 80 years of age. It has not yet been elucidated why the lens loses its transparency and becomes opaque. The well-organized network structure of component proteins is involved in the maintenance of lens transparency. Aggregation of $\alpha$-crystallin, a component protein, causes opacity, reducing lens function and affecting the field and power of vision [9]. Notably, lens proteins are never replaced during a lifetime. In order to prevent opacity, it would be effective to express $\alpha$-crystallin in the lens.

The alopecia is closely related to the protein levels of type 17 collagen, heat shock protein 47 (HSP47), and 5 $\alpha$-reductase. Proteolysis of type 17 collagen in hair follicle stem cells causes miniaturization of hair follicles, resulting in aging-associated hair loss [10]. High expression of HSP47, which is a collagen-specific chaperone, can suppress this proteolysis, inhibiting alopecia. $5 \alpha$-reductase binds to testosterone and converts it to dihydrotestosterone (DHT) which promotes hair loss and thinning [11]. These observations suggest that inhibition of $5 \square \alpha$-reductase activity and expression of type 17 collagen and HSP47 would suppress alopecia.

The obesity seems to be closely related to expression levels of uncoupling protein-1 (UCP1) and irisin. Higher expression of UCP1 in the mitochondria of adipocytes raises body temperature and increases the number of mitochondria, resulting in the reduction of body fat [12]. Irisin is a peptide hormone secreted from skeletal muscle cells in response to the exercise and induces the differentiation from fat-storing white adipocytes to fat-burning brown adipocytes, leading to weight loss [13]. Therefore, substances that stimulate irisin secretion would have weight loss effects. 
Synthesis of melanin, which causes pigmentation of the skin, is promoted by various exogenous and endogenous stimuli. When humans are exposed to the ultraviolet light in sunlight, stress, and air pollution, excess amounts of ROS are generated in the skin surface, and stimulate melanocytes to produce tyrosinase, which reacts with tyrosine to produce melanin. Capturing excess amounts of ROS with antioxidants suppresses melanin production [14].

Our aim was to find new functionality from the food with the high ORAC value. We have previously found that black raspberry extract (BRE) contains a large amount of delphinidin, which can induce the anti-aging-related protein, sirtuin [15]. To evaluate anti-aging effects of berry extracts in this study, we investigated their effects on the induction of $\alpha$-crystallin expression for anti-aging of the eye, expression of type 17 collagen and HSP47 and inhibition of $5 \alpha$-reductase for alopecia, induction of UCP1 expression and irisin secretion from skeletal muscle cells for weight loss, and tyrosinase activity in melanocytes. The results suggested that BRE has various anti-aging effects through their antioxidant action.

\section{MATERIALS AND METHODS}

Preparation of berry extracts: Frozen Blabina (a powdered formulation containing BRE: trademark registration number 5735928), BRs, blueberries (BBs), and raspberries (RBs) were provided in a frozen state from INNATUS Co. Approximately $100 \mathrm{~g}$ of each berry was mixed with 5 volumes of $30 \%$ ethanol (approximately $500 \mathrm{~mL}$ ), blended at $8,000 \mathrm{rpm}$ for $30 \mathrm{~min}$ followed by slow stirring at room temperature for $24 \mathrm{hrs}$. After filtration through mesh with the pore size of $150 \mathrm{~nm}$, a 30\% ethanol extract was obtained for ORAC measurements. Blabina was dissolved in $30 \%$ ethanol at $9 \mathrm{mg} / \mathrm{mL}$, and processed in the same manner.

Ethanol in the extract was evaporated before use of the extracts in experiments. The dry weights of the $30 \%$ ethanol extracts and the ethanol-removed samples were measured after a freeze-dried, and the concentrations of these original liquids were calculated as $9 \mathrm{mg} / \mathrm{ml}$ and 11.5 $\mathrm{mg} / \mathrm{ml}$ respectively. Serial dilutions of ethanol-removed samples were made with ultrapure water and added to the cell culture at $1 / 100$ of the medium volume.

Cell culture: Human follicle dermal papilla cells (C-12071, PromoCell), skeletal muscle cells (C-12530, PromoCell), and juvenile foreskin melanocytes (C-12400, PromoCell) were cultured in Follicle Dermal Papilla Cell Growth Medium Supplement Pack, C-39620, Skeletal Muscle Cell Growth Medium Supplement Pack, C-39360, and Melanocyte Growth Medium Supplement Pack, C-39410, respectively (all from PromoCell), at $37^{\circ} \mathrm{C}$ in a $5 \% \mathrm{CO}_{2}$ incubator. B-3 cells 
(ATCC, CRL-11421), human lens cells transformed with an adenovirus 12-SV40 virus hybrid, and adipocytes differentiated from 3T3-L1 cells as described below were cultured in Dulbecco's modified Eagle's medium (DMEM) with $10 \%$ fetal calf serum (FCS) at $37^{\circ} \mathrm{C}$ in a $5 \% \mathrm{CO}_{2}$ incubator. Cells were harvested with $0.25 \%$ trypsin and $0.1 \%$ EDTA, seeded onto 24- or 96-well plates at $2 \times 10^{5}$ cells/well, and cultured for 24 hours before use in experiments.

Differentiation of 3T3-L1 cells into adipocytes: 3T3-L1 cells were differentiated into adipocytes according to the method of Rubin et al. [16]. Briefly, 3T3-L1 cells were cultured for 3 days in DMEM containing 10\% FCS, 1 mM 3-isobutyl-1-methylxanthine (IBMX), $1 \mu \mathrm{M}$ dexamethasone, and $100 \mathrm{nM}$ insulin (all from Wako Pure Chemical Industry) at $37^{\circ} \mathrm{C}$ in a $5 \%$ $\mathrm{CO}_{2}$ incubator. After the cell culture medium was exchanged for a DMEM culture medium containing $10 \%$ FCS, cells were further cultured for 7 days. Differentiation of 3T3-L1 cells into adipocytes was confirmed by measuring glycerol-3-phosphoric acid dehydrogenase (GPDH) activity in cells, which was increased by about 1000 times. GPDH activity was measured with the GPDH activity assay kit (Code \#; 309-06141, Wako Pure Chemical Industry).

ORAC: The ORAC assay was conducted by measuring the fluorescent intensity of fluorescein degraded by ROS over time. When an antioxidant substance is present in this assay system, the decline rate of the fluorescent intensity slows. Trolox (6-hydroxy-2,5,7,8-tetramethylchroman-2-carboxylic acid) was used as a standard antioxidant substance, and the antioxidant capacities of samples were calculated in comparison to the decline rate of the standard. The results are shown as the amount of Trolox $(\mu \mathrm{M})$ per 1 gram of the sample extracted with $30 \%$ ethanol, in the unit of $\mu \mathrm{M}$ TE (Trolox equivalent)/g.

\section{Quantitative reverse transcription-polymerase chain reaction (qRT-PCR) analysis of type} 17 collagen, $\mathrm{HSP} 47, \mathrm{UCP1}$, and $\alpha$-crystallin expression: Total RNA was extracted from cells using TRIzol reagent (Ambion). The extracted RNAs were reverse-transcribed into cDNAs using PrimeScript RT Master Mix (Takara) following the manufacturer's instructions and amplified using SYBR Premix EX Taq II (Takara). Reactions were performed in the final volume of $50 \mu \mathrm{L}$ (25 $\mu \mathrm{L}$ of $2 \times \mathrm{SYBR}$ Green Mix, $1 \mu \mathrm{L}$ cDNA, $2 \mu \mathrm{L}$ primer pair mix ( $5 \mathrm{pmol} / \mu \mathrm{L}$ for each primer), and $22 \mu \mathrm{L} \mathrm{H} \mathrm{H}_{2} \mathrm{O}$ ). Each PCR was performed under the following conditions: $95^{\circ} \mathrm{C}$ for $30 \mathrm{sec}$, followed by 50 cycles of $95^{\circ} \mathrm{C}$ for $5 \mathrm{sec}$ and $60^{\circ} \mathrm{C}$ for $30 \mathrm{sec}$. Relative gene expression was calculated using the $\Delta \Delta \mathrm{Ct}$ method, and the housekeeping gene GAPDH was used for 
normalization. The primers used in RT-PCR are shown in Table 1. Significant differences were judged when the $\Delta \Delta \mathrm{Ct}$ value was $>2$.

Table 1. Primers for PCR

\begin{tabular}{ll}
\hline \multicolumn{1}{c}{ Gene } & \multicolumn{1}{c}{ Primer } \\
\hline a-Crystallin & $\begin{array}{l}\text { Forward; CCT GGT ATG GAC AGG ACC TC } \\
\text { Reverse; GGA GGA AAT TGCTGT CAA GG }\end{array}$ \\
\hline Type17 Collagen & $\begin{array}{l}\text { Forward; GAG CTG ACT TTG CTG GAG GT } \\
\text { Reverse; GTCACG TTG CTG TAG GCA GA }\end{array}$ \\
\hline Hsp47 & Forward; CCC TGAAAG TCC CAG ATCAA \\
& Reverse; GGG AGA GGTTGG GAT AGA GC \\
\hline UCP-1 & $\begin{array}{l}\text { Forward; AGG CAC CCA TCA CCA ATG AGG CTT G } \\
\text { Reverse; TGGTGCAGT TTG TCCACT GGG CTT C }\end{array}$ \\
\hline GAPDH & $\begin{array}{l}\text { Forward; AGG GCT GCT TTT AAC TCT GGT } \\
\text { Reverse; CCC CAC TTGATT TTG GAG GGA }\end{array}$ \\
\hline
\end{tabular}

Inhibitory activity against 5 $\alpha$-reductase: As inhibition of $5 \alpha$-reductase suppresses DHT production, we measured the amount of DHT produced using a DHT enzyme-linked immunosorbent assay (ELISA) Kit (E18-220, Immunospec) according to the manufacturer's instructions.

Quantitation of UCP1 and irisin by ELISA: To quantify the expression levels of UCP1 and irisin in the cell, UCP1 (MBS101050, MyBioSource) and irisin ELISA Kit (EK-067-52, Phoenix Pharmaceuticals, Inc.) were employed according to the manufacturers' instructions.

Inhibition of tyrosinase activity: Using L-tyrosine (Sigma) as a substrate, we measured the amount of dopachrome produced by tyrosinase. L-tyrosine $(33.3 \mu \mathrm{L}$ of $2.5 \mathrm{mM})$ was added to 60 $\mu \mathrm{L}$ of $0.1 \mathrm{M}$ phosphate buffer, $\mathrm{pH}$ 6.5. After addition of $3.3 \mu \mathrm{L}$ of L-tyrosine substrate solution, the mixture was stirred, and the enzymatic reaction was started by adding $3.3 \mu \mathrm{L}$ of tyrosinase (approximately $1300 \mathrm{U} / \mathrm{mL}$ ). The temperature inside a plate reader was set at $25^{\circ} \mathrm{C}$. The inhibitory activity was evaluated using the absorbance of dopachrome $(475 \mathrm{~nm})$ synthesized by tyrosinase $[17,18$.$] . Vitamin \mathrm{C}(200 \mathrm{mg} / \mathrm{ml})$ was used as a positive control. 
Statistical analysis: Results obtained in this study are presented as mean \pm SD. Statistical significance was determined using Student's $t$-test, and the difference was considered statistically significant when $\mathrm{P}<0.05$.

\section{RESULTS}

Measurement of antioxidant activity of berry extracts by ORAC: When ORAC values of 3 berry extracts were measured, their values were higher than that of typical antioxidant foods [2] (Table 2). Of 3 berry extracts, BBE had the highest value. Since $0.1 \%$ of ethanol affected the growth of various cultured cells (data not shown), ethanol was evaporated from each sample before use with cultured cells in the subsequent experiments.

\section{Table 2. Estimation of ORAC}

\begin{tabular}{|l|c|}
\hline Sample & ORAC $(\mu \mathrm{MTE} / \mathrm{g})$ \\
\hline Blackraspberry extract (BRE) & 62 \\
\hline Blueberry extract (BBE) & 66 \\
\hline Raspberry extract (RBE) & 49 \\
\hline
\end{tabular}

Induction of $\alpha$-crystallin expression in lens cells: When human lens cells transformed with an adenovirus 12-SV40 virus hybrid were incubated with serially diluted Blabina and berry extracts, mRNA expression levels of $\alpha$-crystallin in the cell, which was analyzed by qRT-PCR, was markedly increased by Blabina and BRE 1 hour after incubation (Fig. 1). The increase was observed at 100,000-fold dilution and remained at least 12 hours' incubation (Fig. 1). Thus, Blabina and BRE had higher $\alpha$-crystallin induction potency than the other berry extracts. 


\section{Blabina}

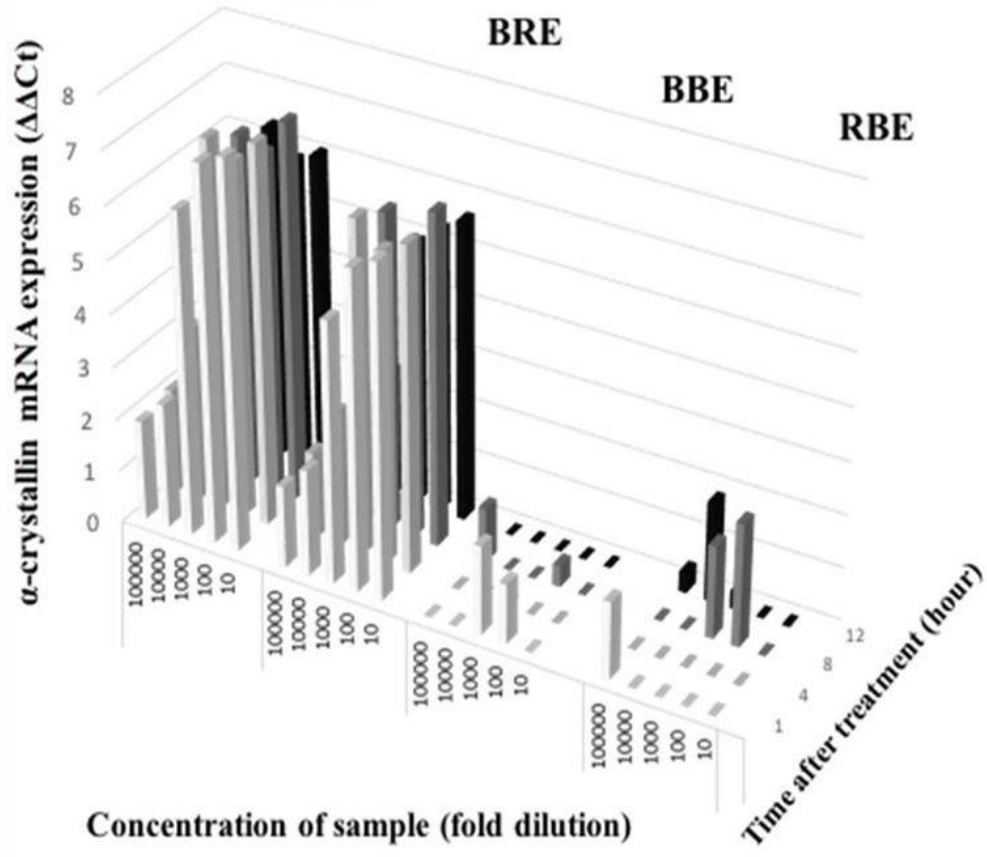

Figure 1. Expression of $\alpha$-crystallin mRNA analyzed by quantitative RT-PCR. Human lens cells transformed with an adenovirus 12-SV40 virus hybrid were incubated with Blabina, BRE, BBE, and RBE for $37^{\circ} \mathrm{C}$ for the time indicated, and expression levels of $\alpha$-crystallin mRNA were determined and shown as the ratio to the expression $(\Delta \Delta \mathrm{Ct})$ in the control at time 0 .

Stimulation of cell growth of follicle dermal papilla cells by berry extracts: When follicle dermal papilla cells were incubated with Blabina and 3 berry extracts, cell growth was increased by $3-20 \%$ in a concentration-dependent manner (Fig. 2).

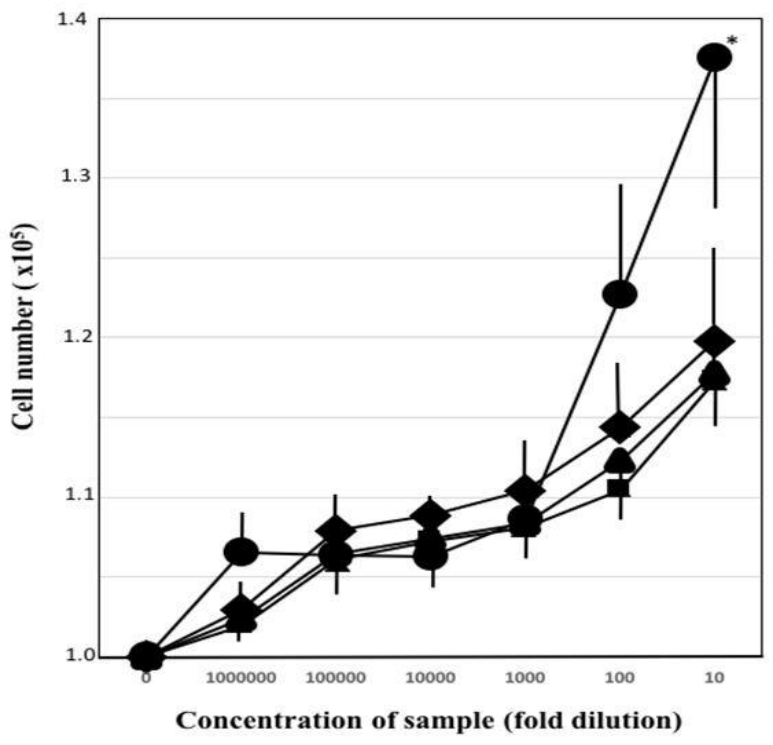

$\bullet=$ Blabina; $\boldsymbol{\Delta}=\mathrm{BRE} ; \boldsymbol{\boldsymbol { }}=\mathrm{BBE} ; \bullet=\mathrm{RBE} . * \mathrm{P}<0.001$ vs BRE, BBE, and RBE. 
Figure 2. Stimulation of cell growth of follicle dermal papilla cells by berry extracts. Human follicle dermal papilla cells were incubated with berry extracts at $37^{\circ} \mathrm{C}$ for 48 hours, and cell growth was evaluated by counting cell number with Countess (Invitrogen).

Stimulation of type 17 collagen and HSP47 mRNA expression in follicle dermal papilla cells by berry extracts: Figure 3 shows the effects of BRE on type 17 collagen and HSP47 mRNA expression levels in follicle dermal papilla cells. Both mRNA expression levels were elevated after 1-4 hours of treatment with 1,000-fold diluted BRE and declined by 8-12 hours.

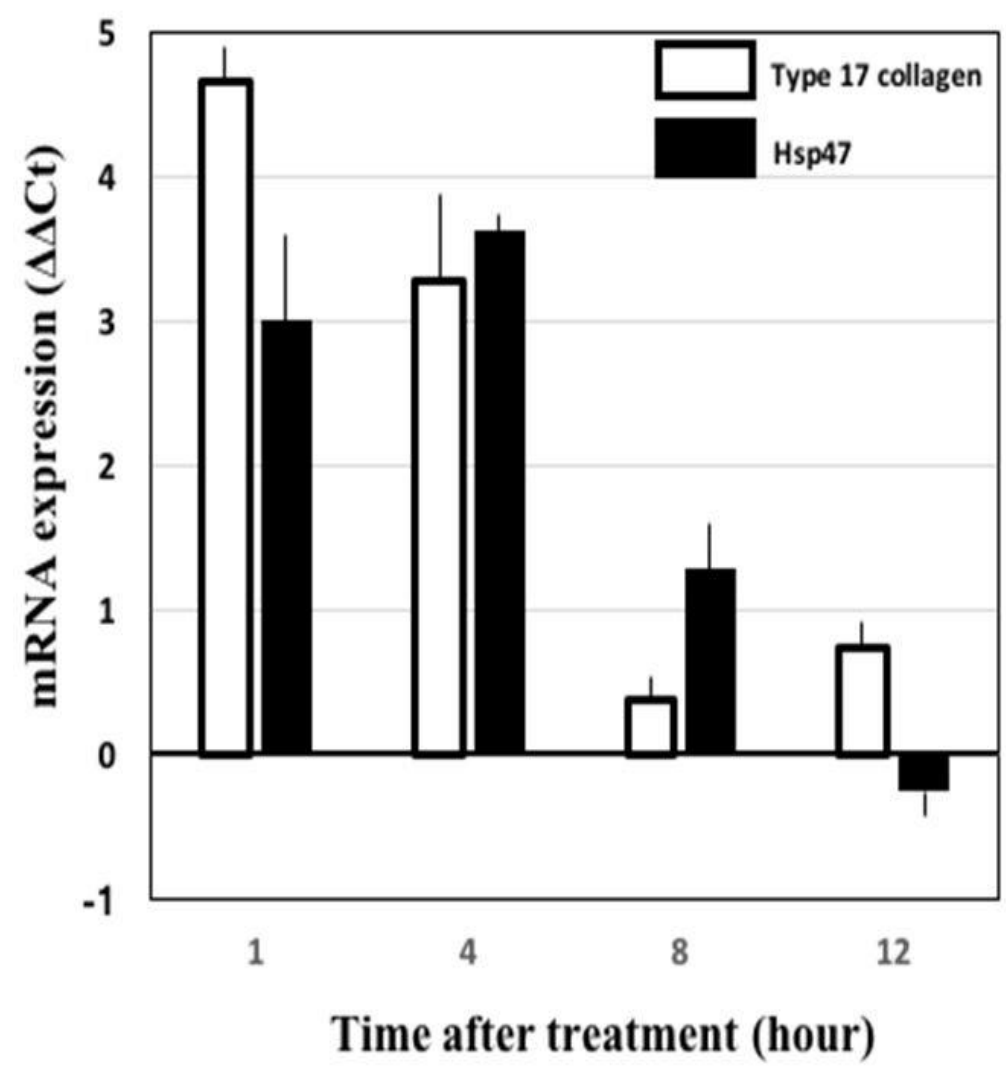

Figure 3. Stimulation of type 17 collagen and HSP47 mRNA expression in follicle dermal papilla cells by BRE. Follicle dermal papilla cells were treated with 1,000-fold diluted BRE for the time indicated, and expression levels of type 17 collagen and HSP47 mRNAs were analyzed by qRT-PCR. White column $=$ type 17 collagen $;$ black column $=H s p 47$. The elevation of these mRNA expression levels was also observed when the cell was treated with other berry extracts including Blabina (Fig. 4). Blabina and BRE showed higher potency than BBE and RBE.

Inhibition of $5 \alpha$-reductase activity by berry extracts: $5 \alpha$-reductase catalyzes the conversion of testosterone to DHT that promotes hair loss and thinning [11]. It has been reported that the pharmaceutical products, finasteride and dutasteride, promote hair growth by inhibiting $5 \alpha$-reductase activity [24]. These reports suggest that $5 \alpha$-reductase is the target molecule to 
promote hair growth. Interestingly, Blabina and 3 berry extracts inhibited $5 \alpha$-reductase in a dose-dependent manner, and the inhibition was observed within 1 hour after treatment (Fig. 5). Of these 4 extracts, BRE and Blabina showed stronger inhibition than BBE and RBE.

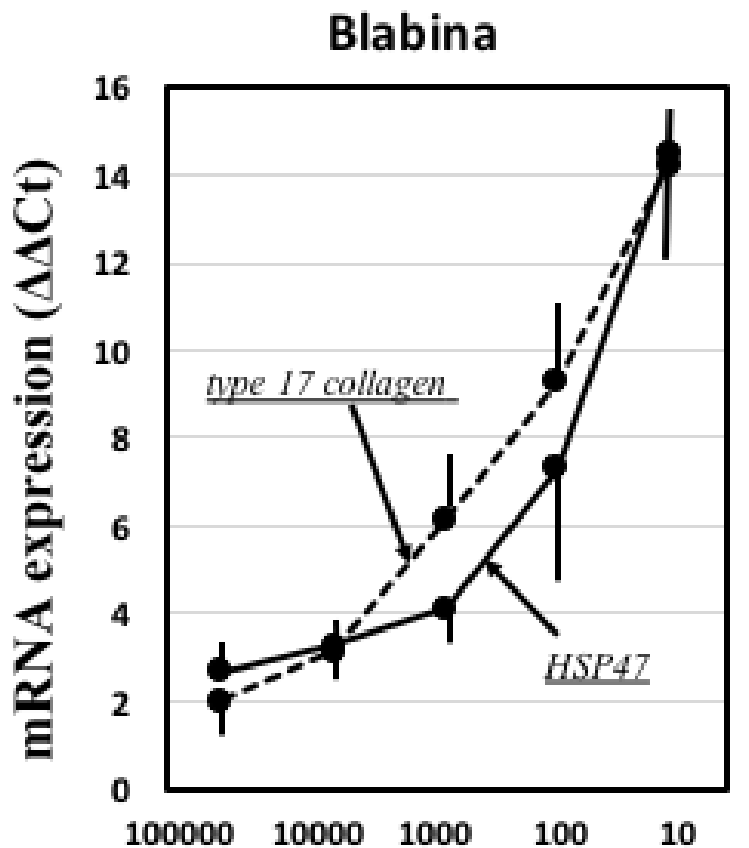

Concentration of sample (fold dilution)

BBE

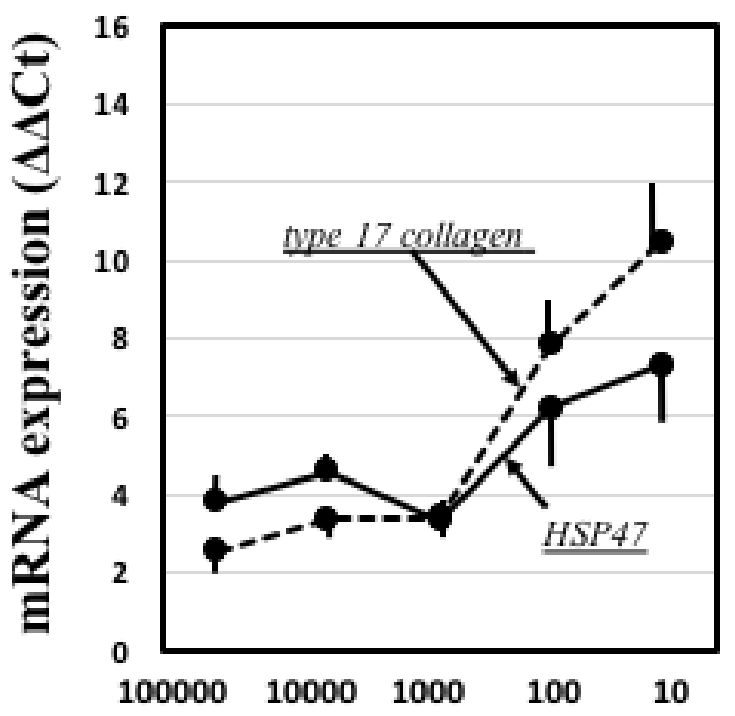

Concentration of sample (fold dilution)

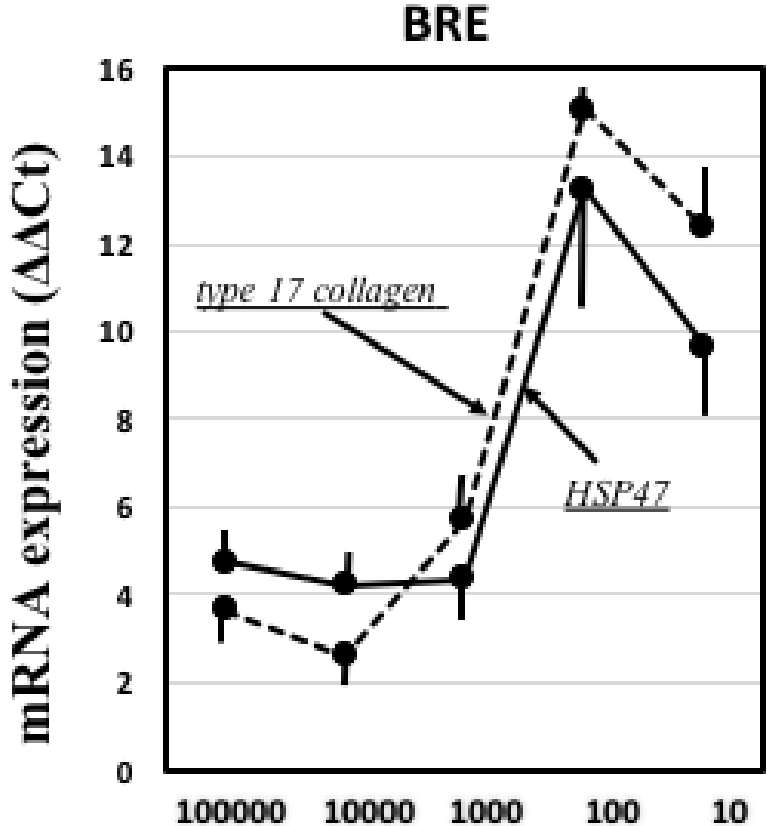

Concentration of sample (fold dilution)

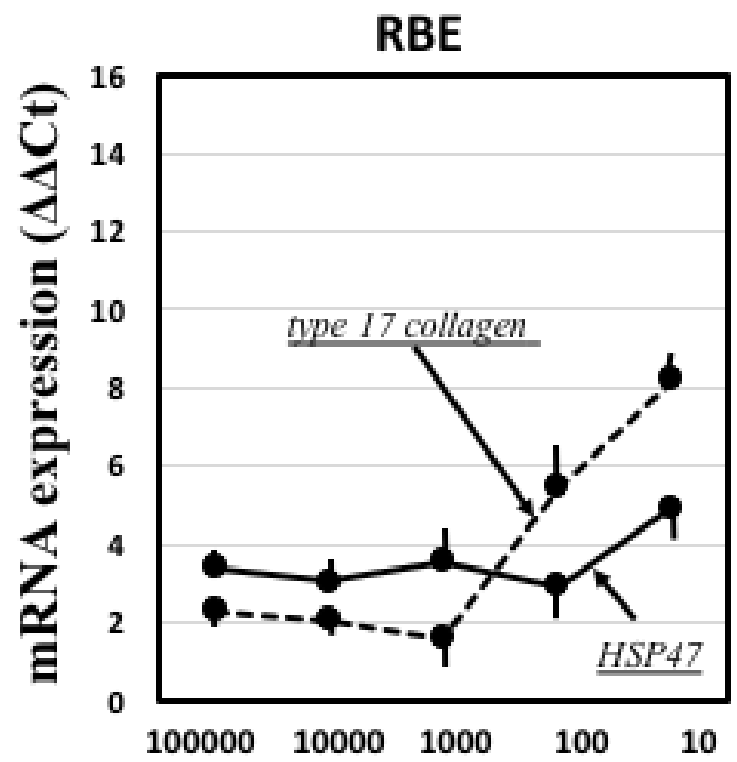

Concentration of sample (fold dilution)

Figure 4. Stimulation of type 17 collagen and HSP47 mRNA expression in follicle dermal papilla cells by berry extracts. Follicle dermal papilla cells were treated with serially diluted Blabina and berry extracts for 1 hour, and expression levels of type 17 collagen and HSP47 mRNAs were analyzed as in Figure 3. mRNA expression levels were calculated relative to the 
expression level $(\Delta \Delta \mathrm{Ct})$ in the untreated control cells. Solid line=type 17 collagen; dotted line= HSP47.

(a) Blabina

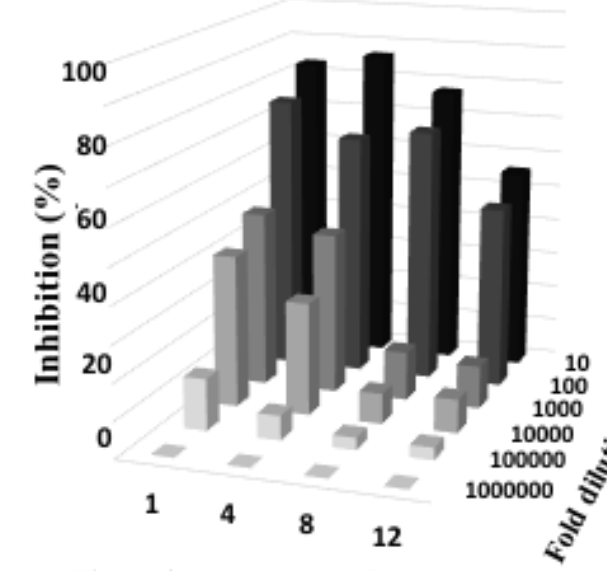

Time after treatment (hour)

(c) BBE

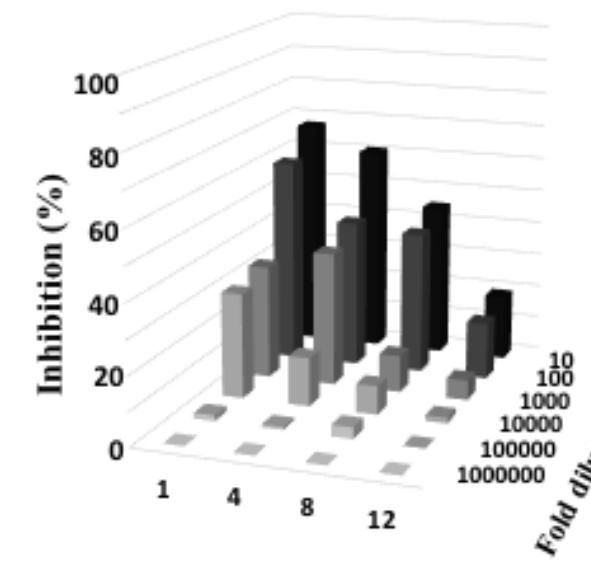

Time after treatment (hour) (b) BRE

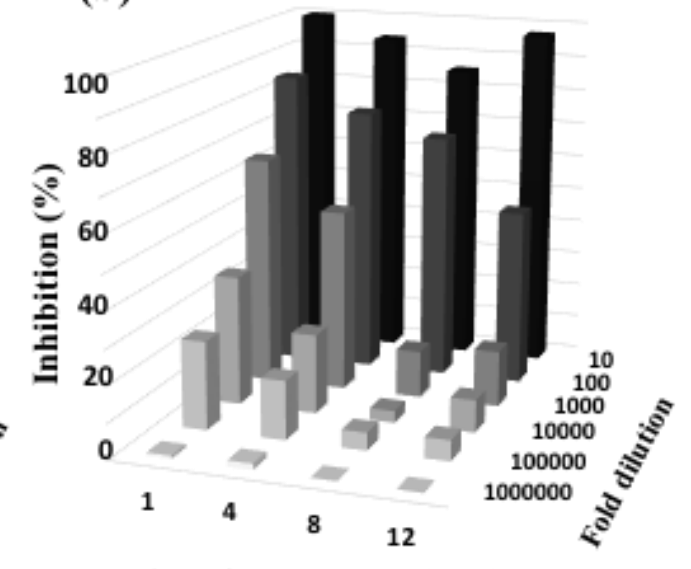

Time after treatment (hour) (d) RBE

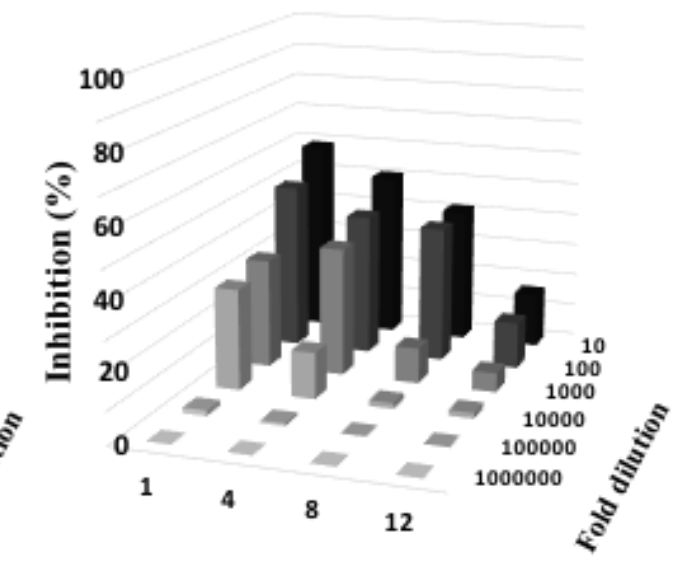

Time after treatment (hour)

Figure 5. Inhibition of $5 \alpha$-reductase in human follicle dermal papilla cells by berry extracts. Follicle dermal papilla cells were treated with serially diluted Blabina and berry extracts for the time indicated, and 5 $\alpha$-reductase activity was determined as described in the Materials and Methods. The maximum inhibition by BRE (10-fold dilution, at 1 hour), $20 \mathrm{pg} / \mathrm{mL}$, was set as $100 \%$ inhibition compared with the activity in control cells, $140 \mathrm{pg} / \mathrm{ml}$.

Induction of $U \boldsymbol{C P 1}$ mRNA expression in adipocytes: All 4 samples increased UCP1 mRNA expression levels in a concentration-dependent manner, and Blabina had the strongest effect (Fig. 6). Consistent with this result, the $U C P 1$ protein secreted from adipocytes was increased by the treatment of the cell with berry extracts in a concentration-dependent manner (Fig. 7). 


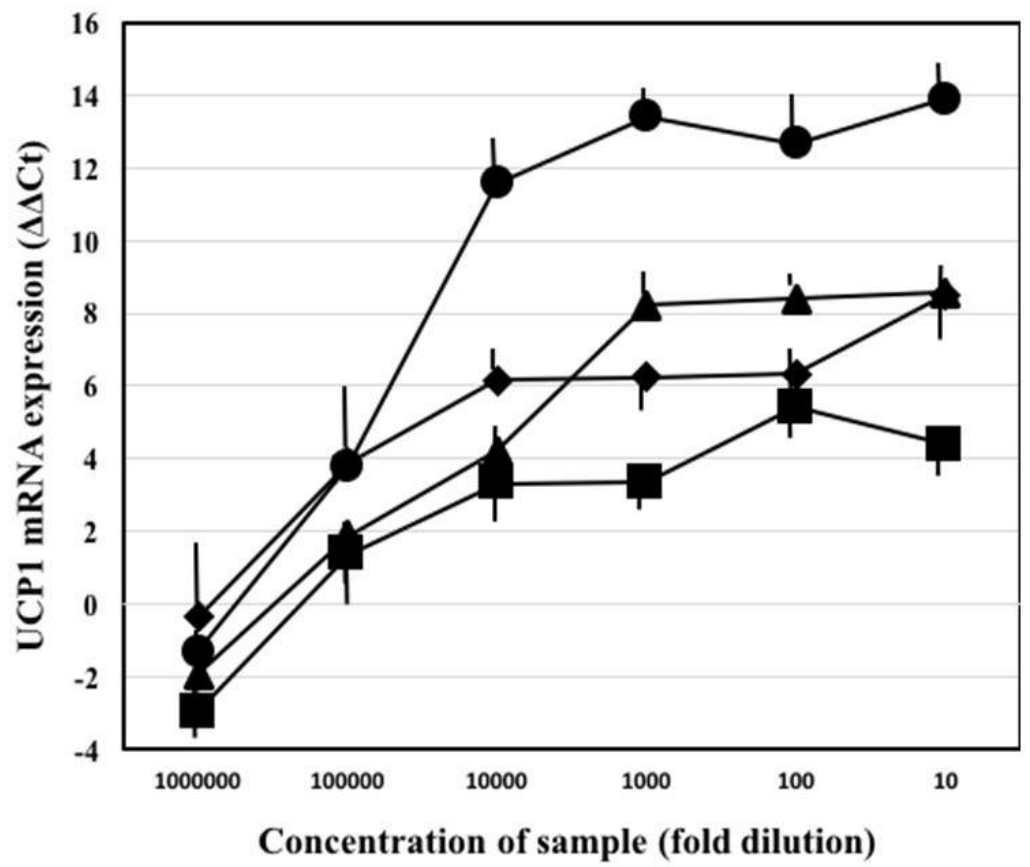

$\bullet=$ Blabina; $\boldsymbol{\Lambda}=\mathrm{BRE} ; \boldsymbol{\bullet}=\mathrm{BBE} ; \boldsymbol{\bullet}=\mathrm{RBE}$.

Figure 6. Induction of $U C P 1$ mRNA expression in adipocytes. Adipocytes were treated with Blabina and berry extracts for 1 hour, and expression levels of UCP1 mRNA were measured by qRT-PCR. The expression levels were calculated relative to the expression level at time $0(\Delta \Delta \mathrm{Ct})$.

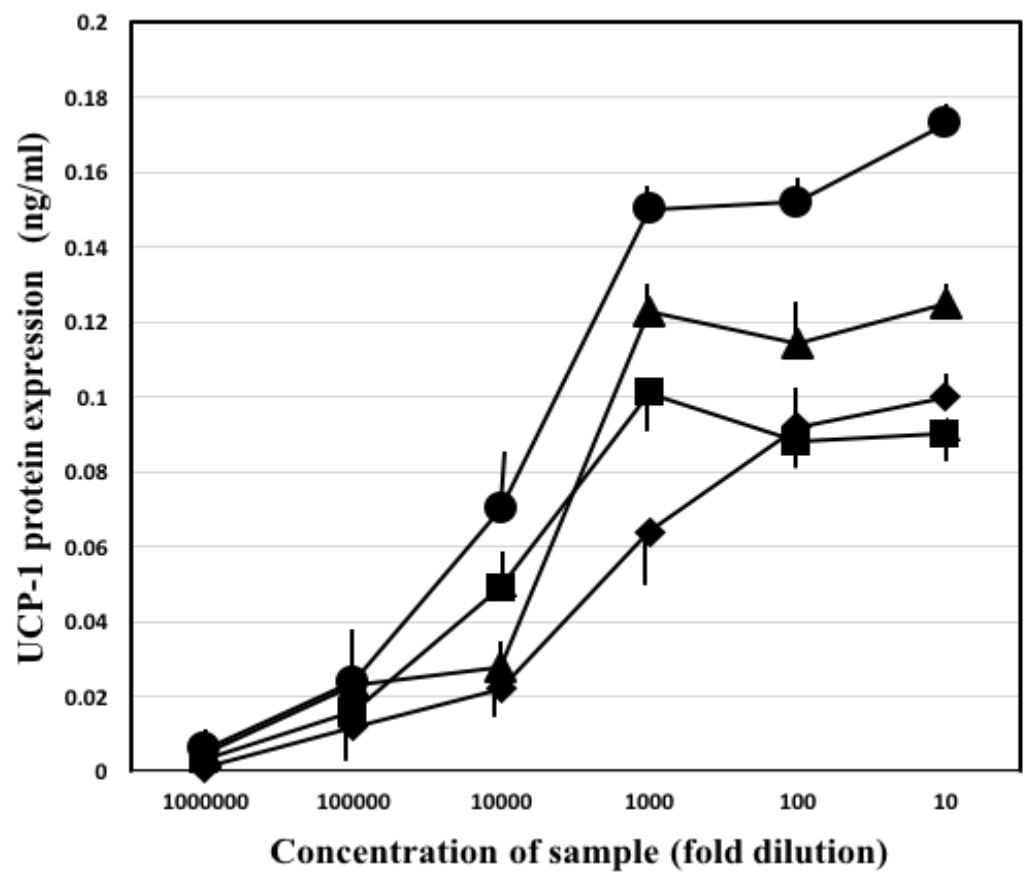

$\bullet=$ Blabina; $\boldsymbol{\Lambda}=$ BRE; $\boldsymbol{\bullet}=\mathrm{BBE} ; \bullet=\mathrm{RBE}$.

Figure 7. Stimulation of $U C P 1$ protein secretion from adipocytes by berry extracts. Adipocytes were treated with 1,000-fold diluted berry extracts for 1 hour, and the $U C P 1$ protein secreted was 
quantitated by ELISA. The amount of UCP1 secreted from the non-treated control cells was subtracted from that secreted from berry extract-treated cells.

Stimulation of irisin secretion from skeletal muscle cells: When skeletal muscle cells were incubated with berry extracts, all extracts tested were found to significantly stimulate the irisin secretion from the cell (Fig. 8). Additionally, blabina and BRE demonstrated the stronger effect compared with other berry extracts, suggesting that these berry extracts are effective to prevent obesity.

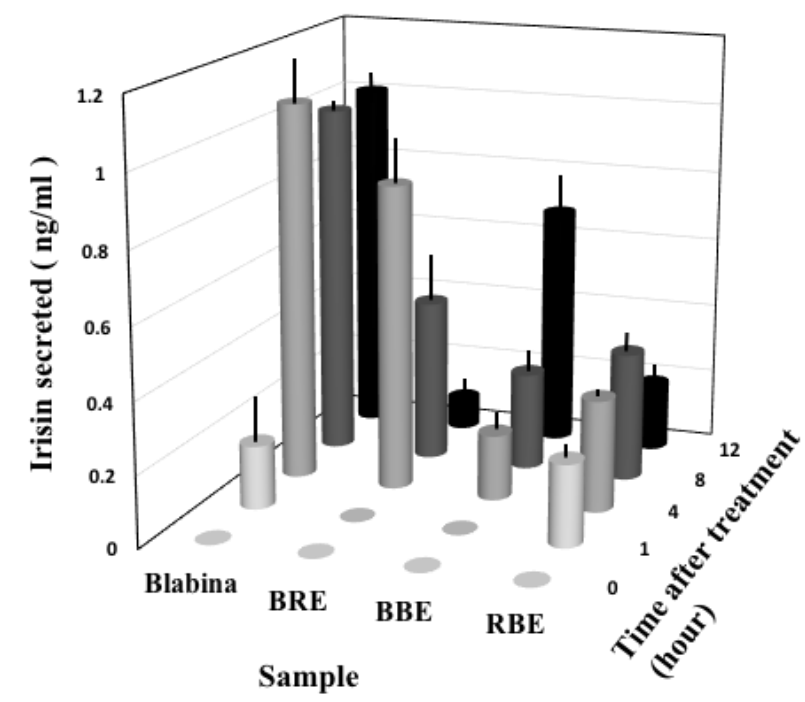

Figure 8. Stimulation of irisin secretion from adipocytes by berry extracts. Adipocytes were treated with berry extracts for 1 hour, and irisin secreted from the cell was quantitated by ELISA. The amount of irisin secreted from the non-treated control cells was subtracted from taht secreted from berry extract-treated cells.

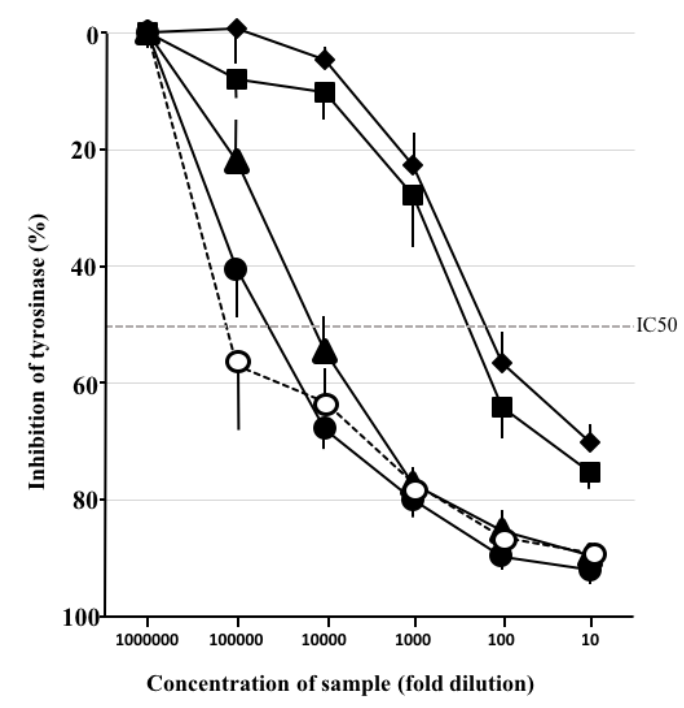

$\bullet=$ Blabina; $\boldsymbol{\Lambda}=\mathrm{BRE}$; $\mathbf{-}$ BBE; $\bullet=\mathrm{RBE} ; \bigcirc=$ vitamin-C as positive control. 
Figure 9. Inhibition of melanocyte tyrosinase activity by berry extracts. Melanocytes were treated with serially diluted berry extracts for 48 hours and tyrosinase activies were determined as described in Materials and Methods. Vitamin C was also tested as a positive control in this experiment. Initial concentration of vitamin C was $200 \mathrm{mg} / \mathrm{ml}$.

Inhibition of tyrosinase activity of melanocytes by berry extracts: To evaluate the effect of berry extracts on tyrosinase activity in comparison with that of vitamin $\mathrm{C}$, melanocytes were treated with serially diluted berry extracts and tyrosinase activity was determined. All berry extracts tested, including vitamin $\mathrm{C}$, inhibited the tyrosinase activity in a concentration-dependent manner (Fig. 9). The inhibitory potency of blabina and BRE was higher than that of RBE and comparable to that of vitamin C: IC50s were about 50,000-, 10,000-, 200-, and 100-fold dilutions for Blabina, BRE, BBE, and RBE respectively. Furthermore, maximum inhibition by blabina and BRE was as high as $90 \%$.

\section{DISCUSSION}

We examined whether they have anti-aging effects on cataract, alopecia, skin whitening, and weight loss and if those effects correlate with their antioxidant activities.

Various factors are involved in the long-term maintenance of the eye lens function, although the precise mechanisms have not yet been elucidated. The component protein of the lens, $\alpha$ -crystallin, has a chaperone effect preventing the aggregation of $\beta$-and $\gamma$-crystallin [19]. Moreover, it has been reported that aspirin suppresses lens opacity through the chaperone activity of $\alpha$-crystallin in a naphthalene-induced cataract rat model [20]. These reports led us to speculate that Blabina and BRE are good candidates to prevent or cure the cataract.

It has been reported that activated human follicle dermal papilla cells secrete fibroblast growth factor 7 (FGF-7), which stimulates the proliferation of hair matrix cells, and vascular endothelial growth factor (VEGF), which promotes angiogenesis, in order to promote hair formation [21, 22]. These reports and our observation raise a possibility that Blabina and berry extracts promote hair formation by stimulating the release of FGF-7 and/or VEGF. This result is consistent with the report demonstrating that cells missing the HSP47 gene (SERPINH1) cannot produce collagen [23].

As shown in Fig. 4, the elevation of type 17 collagen and HSP47 mRNA expression levels was also observed when the cell was treated with other berry extracts including Blabina. Blabina and BRE showed higher potency than BBE and RBE.

Accordingly, it is possible that these berry extracts have potency to stimulate hair growth. As we did not compare the potencies of berry extracts with those of the already approved products, finasteride and dutasteride [25], in this study future experiments should explore this. 
It has been reported that the UCP1 expression level is very low in obese animals and increased in animals that do not develop the diet-induced obesity [26]. Additionally, it has been reported that mice in which the UCP1 expression level is artificially lowered induce obesity, while mice in which the UCP1 expression level is elevated lose weight [26, 27.]. Therefore, UCP1 is believed to play an important role in energy consumption and the progress of obesity [27]: UCP1 promotes the metabolism from free fatty acids to heat energy, thereby decreasing the body fat. These reports led us to examine the effects of berry extracts on UCPI mRNA expression levels in adipocytes.

Exercise increases irisin secretion from the skeletal muscle [28]. Irisin acts on the white adipose tissue to stimulate the UCP1 expression levels through peroxisome proliferator-activated receptor- $\alpha$ (PPAR- $\alpha$ ), and expressed UCP1 stimulates the differentiation of white preadipocytes into brown adipocytes [29, 30]. Importantly, there is a positive correlation between blood irisin concentration and the amount of energy consumption [31]. Moreover, in the elderly, aerobic training elevates irisin levels in the blood, thereby reducing the abdominal visceral fat [32]. Thus, the secretion of irisin from adipocytes is important to prevent obesity.

Vitamin $\mathrm{C}$ is applied to prevent melanin production by inhibiting tyrosinase activity in melanocytes [33]. Furthermore, maximum inhibition by blabina and BRE was as high as 90\%, which has been reported for kojic acid, arbutin and vitamin C [34].

\section{CONCLUSION}

In conclusion, the berry extracts tested in this study were all effective in the anti-aging categories investigated. However, overall blabina and BRE had stronger effects than BBE and RBE. Thus, blabina and BRE are applicable as the anti-aging supplements on cataract, alopecia, skin whitening, and weight loss through their higher antioxidant activities.

List of Abbreviations: BRE, Black raspberry extract; BBE, blueberry extract; RBE, raspberry extract; ORAC, oxygen radical absorbance capacity; UCP1, uncoupling protein-1; DHT, dihydrotestosterone; GPDH, glycerol-3-phosphoric acid dehydrogenase; HSP47, heat shock protein 47; ROS, reactive oxygen species; TE, Trolox equivalents.

Competing Interests: The authors have no financial interest or conflicts of interest.

Authors' Contributions: All authors contributed to this work. H. Banno, Y. Kusumi, K. Dan, and Y. Kanaho designed the research. K. Dan and A. Takada carried out the experiments and analyzed the results. All authors interpreted the results and designed the research strategy. K. Dan, A. Takada and Y. Kanaho prepared the manuscript. 
Acknowledgements and Funding: This research was supported by the health research fund from Orbit limited company. The authors thank Sei-ichi Tanuma, Ph.D. (Director, Genome and Drug Research Center, Tokyo University of Science), many persons in Iwamoto temple (Kochi Prefecture, Japan), and staff in Koshiro company limited Kameoka Plant for their valuable technical support with cultivation and extraction of black raspberry.

\section{REFERENCES}

1. Kevin JB, Colin LM, Ashley IB: Neurodegenerative diseases and oxidative stress. Nat Rev Drug Discov 2004, 3(3):205-14.

2. Slavin JL, Lloyd B: Health benefits of fruits and vegetables. Adv Nutr 2012, 3(4):506-516.

3. Cao G, Alessio HM, Cutler RG: Oxygen-radical absorbance capacity assay for antioxidants. Free Radical Biol Med 1993, 14(3):303-311.

4. ORAC List of foods with high oxygen radical absorption capacity and high antioxidant activity [www.anteaoxidant.com/orac_top100.html]

5. Stefaniak-Vidarsson MM, Gudjoonsdoottir M, Marteinsdottir G, Sigurjonsson OE, Kristbergsson K: Evaluation of bioactivity of fucoidan from laminaria with in vitro human cell culture (THP-1). Functional Foods in Health and Disease 2017, 7(9):688-701.

6. Seydim AC, Guzel-Seydim ZB, Doguc DK, Savas MC, Budak HN: Effects of grape wine and apple cider vinegar on oxidative and antioxidative status in high cholesterol-fed rats. Functional Foods in Health and Disease 2016, 6(9):569-577.

7. Edirisinghe I, Randolph J, Cheema M, Tadapaneni R, Park E, Burton-Freeman B, Kappagoda T: Effect of grape seed extract on postprandial oxidative status and metabolic responses in men and women with the metabolic syndrome - randomized, cross-over, placebo-controlled study. Functional Foods in Health and Disease 2012, 2(12):508-521.

8. Turco I, Bacchetti T, Bender C, Oboh G, Zimmermann B, Ferretti G: Polyphenol content and glycemic load of pasta enriched with Faba bean flour. Functional Foods in Health and Disease 2016, 6(5):291-305.

9. Hipkiss AR: Accumulation of altered proteins and ageing: causes and effects. Exp Gerontol 2006, 41(5):464-473.

10. Matsumura H, Mohri Y, Binh NT, Morinaga H, Fukuda M, Ito M, Kurata S, et al.: Hair follicle aging is driven by transepidermal elimination of stem cells via COL17A1 proteolysis. Science 2016, 351(6273):aad4395. 
11. Camacho-Martinez FM: Hirsutism. In Hair Growth and Disorders. Edited by Blume-Peytavi U, Whiting DA, Trueb RM. Berlin: Springer-Verlag; 2008:368-370.

12. Nedergaard J, Ricquier D, Kozak LP: Uncoupling proteins: current status and therapeutic prospects. EMBO Rep 2005, 6(10):917-921.

13. Bostrom P, Wu J, Jedrychowski MP, Korde A, Ye L, Lo JC, Rasbach KA, et al.: A PGC1- $\alpha$-dependent myokine that drives brown-fat-like development of white fat and thermogenesis. Nature 2012, 481(7382):463-468.

14. Choi MY, Song HS, Hur HS, Sim SS: Whitening activity of luteolin related to the inhibition of cAMP pathway in alpha-MSH-stimulated B16 melanoma cells. Arch Pharm Res 2008, 31(9):1166-1171.

15. Shigeo I, Hiroshi M, Haruo T, Tadao S. A container with a pump that mixes liquid and air to discharge bubbles. 1996, Patent No. 5813576.

16. Rubin CS, Hirsch A, Fung C, Rosen OM: Development of hormone receptors and hormonal respon- siveness in vitro. Insulin receptors and insulin sensitivity in the preadipocyte and adipocyte forms of 3T3-L1 cells. J Biol Chem 1978, 253(20):7570-8.

17. Matsuki M, Watanabe T, Ogasawara A, Mikami T, Matsumoto T: Inhibitory mechanism of melanin synthesis by glutathione. Yakugaku Zasshi 2008, 128(8):1203-1207.

18. Pintus F, Spano D, Corona A, Medda R: Antityrosinase activity of Euphorbia characias extracts. Peer J 2015, 13:e1305.

19. Yan C, Lu Y, Yongxiang J: The protective effects of aspirin on the. ALPHA. -crystalline molecular chaperone-like activity in naphthalene-induced cataract. Yanke Yanjiu 2010, 28:221-224.

20. Andley UP: Crystallins in the eye: Function and pathology. Prog Retin Eye Res 2007, 26(1):78-98.

21. Iino M, Ehama R, Nakazawa Y, Iwabuchi T, Ogo M, Tajima M, Arase S: Adenosine stimulates fibroblast growth factor-7 gene expression via adenosine A2b receptor signaling in dermal papilla cells. J Invest Dermatol 2007, 127(6):1318-25.

22. Lachgar S, Charveron M, Sarraute J, Gall Y, Bonafe JL: Anti-androgens and estrogens: modulators of VEGF expression in cultured hair dermal papilla cells. Exp Dermatol 1999, 8(4):336-338.

23. Ishii H, Mukae H, Kakugawa T, Iwashita T, Kaida H, Fujii T, Hayashi T, et al.: Increased expression of collagen-binding heat shock protein 47 in murine bleomycin-induced pneumopathy. Am J Physiol Lung Cell Mol Physiol 2003, 285(4):L957-963.

24. Hirshburg JM, Kelsey PA, Therrien CA, Gavino AC, Reichenberg JS: Adverse Effects 
and Safety of 5-alpha Reductase Inhibitors (Finasteride, Dutasteride): A Systematic Review. J Clin Aesthet Dermatol 2016, 9(7):56-62.

25. Choi GS, Kim JH, Oh SY, Park JM, Hong JS, Lee YS, Lee WS: Safety and Tolerability of the Dual 5-Alpha Reductase Inhibitor Dutasteride in the Treatment of Androgenetic Alopecia. Ann Dermatol 2016, 28(4):444-450.

26. Saito M: Roles of UCP in the regulation of energy expenditure. Scientific Approach in Obesity-Adiposcience. The $124^{\text {th }}$ Nihon Medical Science Association Symposium Supplement 2001, 62-70.

27. Dalgaad LT, Pedersen O: Uncoupling proteins: functional characteristics and role in the pathogenesis of obesity and Type II diabetes. Diabetologia 2001, 44(8):946-965.

28. Bostrom P, Wu J, Jediychowski MP, Korde A, Ye L, Lo JC, Rasbach KA, et al.: A PGC1- $\alpha$-dependent myokine that drives brown-fat-like development of white fat and thermogenesis. Nature 2012, 48(7382):463-468.

29. Kelly DP: Irisin, light my fire. Science 2012, 336(6077):42-43.

30. Swick AG, Orena S, O’Connor A: Irisin levels correlate with energy expenditure in a subgroup of humans with energy expenditure greater than predicted by fat free mass. Metabolism 2013, 62(8):1070-1073.

31. Motoyuki I, Kiji S, Toshiyuki K, Satoshi F, Takafumi H: Association between exercise training-induced Irisin secretion and reduction of visceral fat. DESCENTE SPORTS Science 2014, 35:113-122.

32. Albrecht E, Norheim F, Thiede B, Holen T, Ohashi T, Schering L, Lee S, et al.: Irisin a myth rather than an exercise-inducible myokine. Sci Rep 2015, 5:8889.

33. Chen X, Haniu A, Kashiwagi T, Watanabe H, Watanabe T, Okamoto Y, Suzuki M, et al.: The evaluation of the synergistic effect of 3-(2,4-dihydroxyphenyl) propionic acid and 1-ascorbic acid on tyrosinase inhibition. Z Naturforsch C 2017, 72(3-4):119-121.

34. Panich U, Tangsupa-a-nan V, Onkoksoong T, Kongtaphan K, Kasetsinsombat K, Akarasereenont P, Wongkajornsilp A: Inhibition of UVA-mediated melanogenesis by ascorbic acid through modulation of antioxidant defense and nitric oxide system. Arch Pharm Res. 2011, 34(5):811-20. 